(2) Open Access Full Text Article

ORIGINAL RESEARCH

\title{
Increased Expression Of SOX2 Predicts A Poor Prognosis And Promotes Malignant Phenotypes In Upper Tract Urothelial Carcinoma
}

This article was published in the following Dove Press journal: Cancer Management and Research

\author{
Zhengqing Bao ${ }^{1-3, *}$ \\ Yonghao Zhan ${ }^{1-4, *}$ \\ Shiming $\mathrm{He}^{\mathrm{I}-3}$ \\ Yifan $\mathrm{Li}^{\mathrm{I}-3}$ \\ Bao Guan ${ }^{1-3}$ \\ Qun $\mathrm{He}^{\mathrm{l-3}}$ \\ Xinyu Yang ${ }^{1-3}$ \\ Xuesong $\mathrm{Li}^{1-3}$ \\ Dong Fang (D) ${ }^{1-3,5}$ \\ Liqun Zhou ${ }^{1-3}$ \\ 'Department of Urology, Peking \\ University First Hospital, Beijing, People's \\ Republic of China; ${ }^{2}$ Institute of Urology, \\ Peking University, National Urological \\ Cancer Centre, Beijing, People's Republic \\ of China; ${ }^{3}$ Beijing Key Laboratory of \\ Urogenital Diseases (Male), Molecular \\ Diagnosis and Treatment Center, Beijing, \\ People's Republic of China; ${ }^{4}$ Department \\ of Urology, The First Affiliated Hospital \\ of Zhengzhou University, Zhengzhou, \\ Henan 450003, People's Republic of \\ China; ${ }^{5}$ Andrology Center, Peking \\ University First Hospital, Beijing 100034, \\ People's Republic of China
}

*These authors contributed equally to this work
Background: The transcription factor SRY-related HMG-box 2 (SOX2) plays important regulatory roles in diverse biological processes (cell proliferation, migration, invasion and tumorigenicity). However, the relationship between SOX2 and upper tract urothelial carcinoma (UTUC) have not been intensively investigated. This study aims to analyze the expression of SOX2 in UTUC as well as the predictive value for prognosis and the effect on tumor aggressiveness of SOX2.

Methods: Formalin-fixed, paraffin-embedded blocks containing samples from 341 patients with UTUC who underwent radical nephroureterectomy (RNU) at our institute were analyzed for SOX2 expression by immunohistochemistry (IHC). Associations between the SOX2 expression level and clinicopathological characteristics, disease-free survival (DFS) and cancer-specific survival (CSS) were analyzed. SOX2 expression in a normal urothelial cell line, urothelial carcinoma cell lines, 16 UTUC tissues and their pair-matched adjacent normal tissues was evaluated by RT-qPCR. Using RNA interference in vitro, the effects of SOX2 inhibition on cell proliferation, migration, invasion and tumorigenicity were determined.

Results: SOX2 expression was significantly upregulated in UTUC tissue samples compared with paired-adjacent nontumorous tissue samples. SOX2 expression was correlated with important clinicopathological features, including tumor stage, tumor grade, tumor architecture and the presence of glandular or sarcoma differentiation, and was an independent predictor of poor DFS and CSS. Further experiments indicated that SOX2 expression was higher in UTUC cell lines than in a normal urothelial cell line. Knocking down SOX2 expression could inhibit malignant phenotypes (cell proliferation, stemness, migration, invasion and tumorigenicity) in UTUC cells.

Conclusion: SOX2 is an independent prognostic marker of poor DFS and CSS in UTUC patients who have undergone RNU. Moreover, these data suggest that SOX2 may be a promising therapeutic target in UTUC.

Keywords: SRY-related HMG-box 2, upper tract urothelial carcinoma, biomarker, prognosis, stemness

\section{Introduction}

Upper urinary tract urothelial carcinoma (UTUC), which includes any carcinoma that arises from the urothelium of the urinary tract between the renal pelvis and the distal ureter, is relatively rare with an approximate annual incidence of 1-2/100,000 in Western countries and accounts for only $5-10 \%$ of all urothelial carcinomas. ${ }^{1,2}$ In general, radical nephroureterectomy (RNU) with excision of the bladder cuff is the standard treatment for UTUC patients. ${ }^{3}$ Unfortunately, many UTUC patients are identified as having locally advanced or high-grade tumors at the time of surgery
Correspondence: Dong Fang; Liqun Zhou Department of Urology, Peking University First Hospital, No. 8 Xishiku St, Xicheng District, Beijing 100034, People's Republic of China

Tel +86-10-83575006

Fax +86-10-6655I726

Email fdmailbox@126.com;

zhoulqmail@sina.com 
(60\% and $70 \%$, respectively). ${ }^{4,5}$ Previous studies have reported that the 5-year cancer-specific survival (CSS) rate ranges from $50-80 \%{ }^{6,7}$ Although prognostic indicators, such as tumor stage, tumor grade, lymph node status, and lymphovascular invasion (LVI), have been found to be the most important factors in predicting the progression and recurrence of UTUC, the biological basis for UTUC is not completely understood. ${ }^{1}$ Therefore, a better understanding of the molecular mechanisms underlying UTUC tumorigenesis and biomarkers for screening could help overcome the limitations of conventionally used prognostic risk factors for UTUC, help clinicians provide individualized prognostications and allow risk-stratified clinical decision-making regarding adjuvant therapy.

As a member of the SRY-related HMG-box (SOX) family, the transcription factor SOX2 comprises an HMG domain and a transcriptional activation domain with the ability to bind DNA. ${ }^{8}$ Aberrant expression of SOX2 has been reported in many types of cancers, and SOX2 plays important regulatory roles in diverse biological processes, such as transcriptional regulation, cell growth and tumorigenesis. Gen et $\mathrm{al}^{9}$ revealed that SOX2 expression is high in esophageal squamous cell carcinoma cell lines and promotes cell proliferation. A previous study demonstrated that SOX2 overexpression in hepatocellular carcinoma causes active Epithelial-to-mesenchymal transition (EMT) and increases invasion and sphere and colony formation capacities. ${ }^{10}$ Recent evidence has shown that SOX2 is correlated with the presence of cancer stem-like cells (CSCs), including bladder cancer. ${ }^{11} \mathrm{CSC}$ s share some fundamental characteristics with normal stem cells, such as differentiation and self-renewal capacities, and are thought to play roles in tumor recurrence and resistance to tumor therapies. ${ }^{12-14}$ Kitamura et $\mathrm{al}^{15}$ conducted an IHC study of 125 UTUC patients, and revealed that SOX2 expression was a prognostic predictor in univariable analyses, but it was not an independent prognostic factor after adjustment for other clinicopathological characteristics. However, they only analyzed in a relatively small number of patients.

This study aims to analyze the expression of SOX2 in UTUC as well as the predictive value for prognosis, based on a high-volume cohort, and the effect on tumor aggressiveness of SOX2.

\section{Materials And Methods}

\section{Patients And Samples}

We retrospectively collected the records of 657 consecutive patients diagnosed histologically with UTUC who received surgical treatment at Peking University First Hospital between January 2006 and December 2013. A total of 316 patients were excluded from this study because of missing follow-up data $(n=48)$, concomitant urothelial carcinoma of the bladder (UCB) $(n=79)$ or other malignancies $(n=13)$, receipt of a treatment other than RNU $(n=101)$ or their largest tumor size $\leq 15 \mathrm{~mm}$ $(n=75)$. Ultimately, 341 patients were enrolled (Figure 1). All patients underwent standard RNU with bladder cuff resection without any preoperative treatment. Routine lymph node dissection was performed when enlarged lymph nodes were found by preoperative imaging or intraoperative observation. Clinicopathological and follow-up data were collected in a database containing the comprehensive medical records of the UTUC patients.

Staging was assessed according to the 2002 Union for International Cancer Control (UICC) TNM classification guidelines. The patients were graded based on the World Health Organization (WHO) 2004 grading system. The estimated glomerular filtration rate (eGFR) was calculated using the modified glomerular filtration rate equation for Chinese patients [eGFR $\left(\mathrm{mL} / \mathrm{min} / 1.73 \mathrm{~m}^{2}\right)=175 \times$ Scr- $1.234 \times$ age0.179 ( $\times 0.79$ if female) $].{ }^{16}$ Preoperative renal function (PRF) was measured and recorded as no CKD $($ GFR $\geq 60)$, early CKD $(60>\mathrm{eGFR} \geq 15)$ or end-stage CKD $(\mathrm{eGFR}<15)$.

For patients who were followed at our institute, their follow-up regimen included cystoscopy every 3 months for the first 3 years. The cystoscopy interval was extended to 1 year thereafter. Chest X-ray, urine cytology, serum creatinine, and abdominal ultrasound or CT/MRI evaluations were performed at the same time. Disease-free survival (DFS) was determined at the last follow-up based on examination results. Cancer-specific survival (CSS) was determined by review of patient medical records and data in the Chinese National Statistical Office database.

In addition, a total of 16 UTUC tissue samples and pair-matched adjacent normal tissue samples were obtained with informed consent from patients who underwent RNU at our institute. All samples were processed by two urological pathologists. All fresh specimens were immediately frozen in liquid nitrogen and then stored in a $-80{ }^{\circ} \mathrm{C}$ freezer prior to RNA isolation. This study approved by the Ethics Committee of Peking University First Hospital, Beijing, China (approval no. 2016-1253). All procedures performed in studies involving human participants were in accordance with the ethical standards of the institutional research committee and the 1964 Declaration of Helsinki and its later amendments, and 


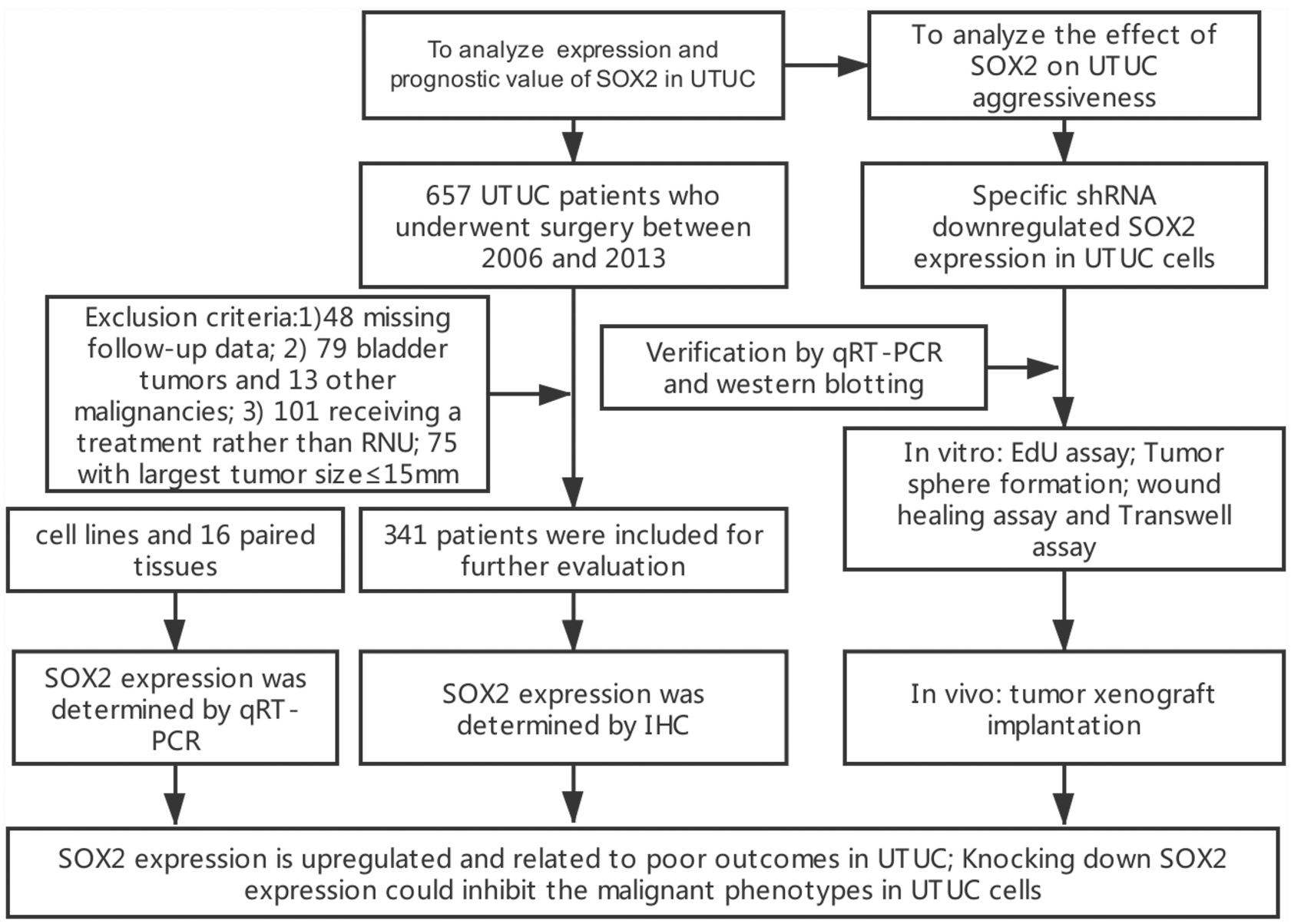

Figure I The REMARK diagram of the study.

written informed consents for review of their medical records were also obtained from all patients.

\section{Immunohistochemistry (IHC)}

Formalin-fixed, paraffin-embedded blocks of 341 UTUC specimens were retrieved from the Department of Urological Pathology. The expression of SOX2 was evaluated by standard IHC protocols. In the case of giant or multiple tumors, only the largest tumor specimen was processed for IHC analysis. Briefly, 4-mm sections from all formalin-fixed, paraffinembedded specimens were deparaffinized with xylene and rehydrated in decreasing concentrations of ethanol. Heatinduced antigen retrieval was performed using sodium citrate in a pressure cooker at $120^{\circ} \mathrm{C}$ for $20 \mathrm{~min}$. After blocking endogenous peroxidases with $3 \%$ hydrogen peroxide in methanol, the sections were incubated with $10 \%$ normal blocking serum in Tris-buffered saline for $20 \mathrm{~min}$. Based on preliminary evaluations, the sections were incubated with an anti-SOX2 antibody (ab92494; 1:200; Abcam, Hong Kong, China) overnight, followed by incubation with a goat anti-rabbit IgG/HRP polymer (PV-9001, ZSGB-BIO, Beijing, China) for $20 \mathrm{~min}$. The sections were then exposed to a diaminobenzidine tetrahydrochloride solution and counterstained with hematoxylin. The stained tissue sections were reviewed and scored by two independent urological pathologists without any prior knowledge of the clinical data of the cohort (X.Y. and Q.H.), disagreements were reconciled by multi-headed consensus review. Positive SOX2 expression was defined as $\geq 10 \%$ tumor cells with positive nuclear staining. ${ }^{15,17}$

\section{Cell Lines And Cell Culture}

UTUC cell lines (UM-UC-14 and MC-SV-HUC T2) and an SV-40-immortalized human uroepithelial cell line (SVHUC-1) were used in our study. The UM-UC-14 cell line (Sigma-Aldrich, St. Louis, MO, USA) was a generous gift from Prof. Kitramura of Toyama University, MC-SV-HUC T2 cells were purchased from ATCC (CRL-9519), and SVHUC-1 cells were purchased from the Institute of Cell Research (Chinese Academy of Sciences, Shanghai, China). UM-UC-14, MC-SV-HUC T2 and SV-HUC-1 
cells were maintained in RPMI-1640 medium (Invitrogen, Carlsbad, CA, USA) supplemented with $10 \%$ fetal bovine serum. Plates were incubated at $37{ }^{\circ} \mathrm{C}$ in a humidified atmosphere of $5 \% \mathrm{CO} 2$.

\section{shRNA Transfection}

Plasmid vector PLKO.1-puro was purchased from BioVector NTCC Inc, Guangzhou, China. The sequences of the related SOX2-shRNA and the negative control were designed and chemically synthesized. The detailed target sequences of shRNA included in this study are shown in Supplementary Table S1. These synthetic related sequences were inserted into PLKO.1-puro vector. Before transfection, the cells were cultured $24 \mathrm{~h}$. Then, the cells were transiently transfected with corresponding vector using Lipofectamine 3000 Transfection Reagent (Invitrogen, Carlsbad, CA, USA) according to the manufacturer's instructions. After $48 \mathrm{~h}$, cells transfected with corresponding vector were harvested for quantitative realtime PCR. Experiments were repeated at least three times.

\section{RNA Isolation And Quantitative Real- Time PCR}

Total RNA was isolated from tissue specimens or transfected cells using Trizol reagent (Invitrogen, Carlsbad, $\mathrm{Ca}, \mathrm{USA}$ ) according to the manufacturer's protocol. The concentration and purity of the total RNA were detected via UV spectrophotometry analysis at $260 \mathrm{~nm}$, and electrophoresis showed the purified RNA was of good quality. cDNA was produced from the total RNA by using SuperScript III ${ }^{\circledR}$ (Invitrogen) according to the instructions. Quantitative real-time PCR was performed using the ABI PRISM 7000 Fluorescent Quantitative PCR System (Applied Biosystems, Foster City, CA, USA) according to the manufacturer's instructions and normalized to $\beta$-actin. The average (range) number of cycles used for the SOX2 and $\beta$-actin Quantitative real-time PCR were 22.00 (18.04-25.27) and 16.62 (13.27-19.15), respectively. The detailed primer sequences included in this study are shown in Supplementary Table S2. The average value of each triplicate was used to calculate the relative amount of SOX 2 by the $2^{-\Delta \Delta C t}$ method. Experiments were repeated at least three times.

\section{Protein Extraction And Western Blot Analysis}

After total-cell lysates were prepared, total protein was subjected to $12 \%$ sodium dodecyl sulfate-polyacrylamide gel electrophoresis (SDS-PAGE) and transferred to polyvinylidenedifluoride (PVDF) membranes. The PVDF membranes were blocked with 5\% nonfat milk and incubated overnight at $4{ }^{\circ} \mathrm{C}$ with a primary anti-SOX2 antibody (ab92494; 1:1000; Abcam, Hong Kong, China) and then incubated with a secondary antibody (1:5000; Abcam, Hong Kong, China). The blots were visualized with enhanced chemiluminescence using an ECL kit (Beyotime Biotechnology, Jiangsu, China).

\section{Ethynyl-2-Deoxyuridine (EdU) Incorporation Assay}

Cell proliferation was determined by an ethynyl-2-deoxyuridine incorporation assay using an EdU Apollo DNA in vitro kit (RIBOBIO, Guangzhou, China) following the manufacturer's instructions. Briefly, $5 \times 10^{4}$ cells/well were seeded in a 24-well plate for $24 \mathrm{~h}$, and then the cells were incubated with $100 \mu \mathrm{l}$ of $50 \mu \mathrm{M}$ EdU per well for $2 \mathrm{~h}$ at $37^{\circ}$ C. Then, the cells were fixed for $30 \mathrm{~min}$ at room temperature using $100 \mu \mathrm{l}$ of a fixative buffer (4\% polyformaldehydein PBS). Subsequently, the cells were incubated with 50 $\mu \mathrm{l}$ of $2 \mathrm{mg} / \mathrm{mL}$ glycine for $5 \mathrm{~min}$, followed by washing with $100 \mu \mathrm{l}$ of PBS. After permeabilization with $0.5 \%$ Triton $\mathrm{X}-100$, the cells were reacted with a $1 \mathrm{X}$ Apollo solution for $30 \mathrm{~min}$ at room temperature in the dark. After that, the cells were incubated with $100 \mu$ l of a $1 \mathrm{X}$ Hoechst 33,342 solution for $30 \mathrm{~min}$ at room temperature in the dark, followed by washing with $100 \mu \mathrm{l}$ of PBS. The cells were then visualized by fluorescence microscopy. Experiments were repeated at least three times.

\section{Tumor Sphere Formation}

UTUC cells were collected after transfection with the appropriate vector for $48 \mathrm{~h}$; then, $2 \times 10^{2}$ UTUC cells were seeded in a 24-well ultralow attachment surface plate (Corning, USA). The UTUC cells were resuspended in RPMI-1640 medium (Invitrogen, Carlsbad, CA, USA) supplemented with $10 \%$ fetal bovine serum and incubated for $7 \mathrm{~d}$ at $37^{\circ} \mathrm{C}$. Finally, the spheres were visualized under an optical microscope (Olympus, Japan) and a confocal laser-scanning microscope (Leica, Germany).

\section{Wound Healing Assay}

Cell motility was determined by a wound healing assay. First, a wound field was created using a sterile 200- $\mu$ pipette tip to scratch cells that were approximately $90 \%$ confluent. The cells were incubated for $24 \mathrm{~h}$ at $37^{\circ} \mathrm{C}$, and then the migration of the cells was 
assessed with a digital camera system. The cell migration distance $(\mu \mathrm{m})$ was calculated by using the software program HMIAS-2000. Experiments were repeated at least three times.

\section{Transwell Assay}

A cell motility assay was performed using a transwell insert ( $8 \mu \mathrm{m}$, Corning). In total, $2 \times 10^{4}$ cells were first starved in $200 \mathrm{~mL}$ of serum-free medium and then placed in uncoated dishes. The lower chamber was filled with $500 \mathrm{~mL}$ of complete medium. The cells were incubated for $48 \mathrm{~h}$ at $37^{\circ} \mathrm{C}$, and then the cells that had migrated to the bottom surface of the filter membrane were stained with a $0.5 \%$ crystal violet solution and photographed in five preset fields per insert. The results represent the average of three independent experiments.

\section{Tumor Xenograft Implantation In Nude Mice}

Animal work was approved by the Institutional Animal Care and Use Committee (IACUC) of Peking University First Hospital (Beijing, China) and conducted in accordance with the recommendations and ethical regulations of the committee. Mice were maintained under standard conditions according to institutional guidelines for animal care. UTUC cells were collected after transfection for $48 \mathrm{~h}$. A total of $5 \times 10^{6}$ UTUC cells were injected subcutaneously into BALB/c-Nude mice. The mice were euthanized after 5 weeks.

\section{Statistical Analyses}

Pearson's test and the chi-square test were used to determine the distribution of categorical variables, and the Mann-Whitney $U$-test was used for continuous variables. CSS and DFS curves were plotted using the KaplanMeier method and analyzed by the log rank test. Univariable analysis was performed by the log rank test, and multivariable analysis was performed using the Cox proportional hazard regression model. Only those variables that were identified as significant in the univariable analysis were included in the multivariable analysis. All experimental data from three independent experiments were analyzed by Student's $t$-test or ANOVA, and the results are expressed as the mean \pm SD. All statistical tests were performed with SPSS 22.0 (IBM Corp., Armonk, NY, USA), and statistical significance was set at $\mathrm{p}<0.05$.

\section{Results}

\section{SOX2 Expression Isupregulated In UTUC}

The relative expression level of SOX2 was determined in a total of 16 patients with UTUC and in different cell lines by real-time qPCR. As shown in Figure 2D, SOX2 expression was upregulated in UTUC tissue samples compared to pair-matched adjacent normal tissue samples. Furthermore, SOX2 expression was upregulated in UTUC cell lines compared to a normal urothelial cell line (Figure 2E). These results indicated that SOX2 may play oncogenic roles in UTUC.
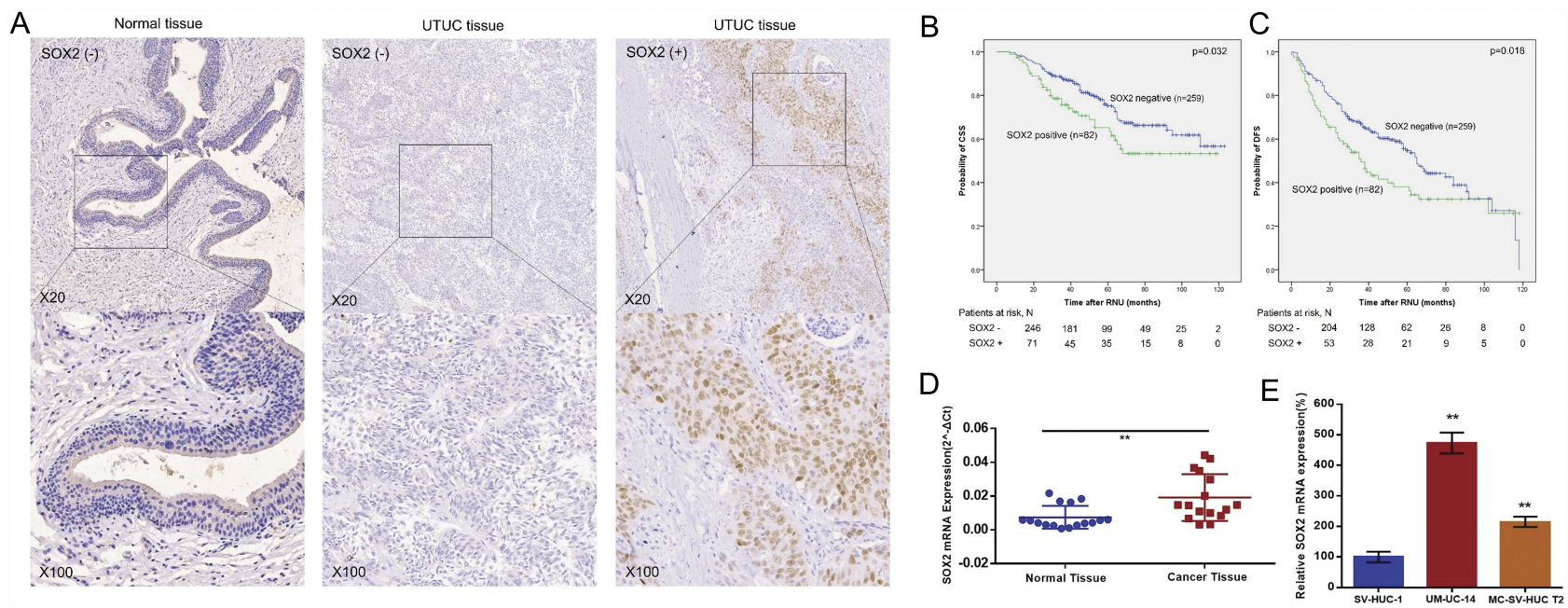

Figure 2 SOX2 expression was upregulated in UTUC. The relative expression levels of SOX2 were detected using immunohistochemistry and real-time qPCR. (A): Representative IHC images are shown. (B): CSS curves were stratified by SOX2 expression. (C): DFS curves were stratified by SOX2 expression. (D). The relative expression level of SOX2 was significantly higher in UTUC tissue samples than in matched normal tissue samples. (E). SOX2 expression levels were higher in UTUC cell lines than in a normal urothelial cell line. ${ }^{* *} p<0.01$. 


\section{Associations Of SOX2 Expression} Assessed By IHC With Clinicopathological Characteristics

The patients included 151 women and 190 men with a median age of 69 (range 29-86) years at the time of surgery and a median follow-up of 51 (range 7-123) months after the surgery. The patient characteristics are presented in Table 1.
Nuclear expression of SOX2 was detected in the tumor cells of $82(24.0 \%)$ UTUC patients (Figure 2A). The correlations of SOX2 expression with clinical characteristics of the patients are summarized in Table 1. We found that high SOX2 expression was correlated with ureter location $(\mathrm{p}<0.001)$, high pathological $\mathrm{T}$ stage $(\mathrm{p}=0.004)$, high tumor grade $(\mathrm{p}<0.001)$, sessile architecture $(\mathrm{p}<0.001)$, and

Table I Associations Between SOX2 Expression And Clinicopathological Characteristics Of The Patients

\begin{tabular}{|c|c|c|c|c|c|}
\hline \multirow[t]{2}{*}{ Variables } & \multirow[t]{2}{*}{ Group } & \multirow[t]{2}{*}{ Total } & \multicolumn{3}{|l|}{ sox2 } \\
\hline & & & Positive & Negative & $\mathbf{p}$ \\
\hline Age & $\begin{array}{l}<69 \\
\geq 69\end{array}$ & $\begin{array}{l}179 \\
162\end{array}$ & $\begin{array}{l}46(25.7 \%) \\
36(22.2 \%)\end{array}$ & $\begin{array}{l}133(74.3 \%) \\
126(77.8 \%)\end{array}$ & 0.453 \\
\hline Gender & $\begin{array}{l}\text { Female } \\
\text { Male }\end{array}$ & $\begin{array}{l}190 \\
151\end{array}$ & $\begin{array}{l}52(27.4 \%) \\
30(19.9 \%)\end{array}$ & $\begin{array}{l}\mid 38(72.6 \%) \\
|2|(80.1 \%)\end{array}$ & 0.107 \\
\hline BMI & $\begin{array}{l}<24.5 \\
\geq 24.5\end{array}$ & $\begin{array}{l}182 \\
158\end{array}$ & $\begin{array}{l}47(25.8 \%) \\
35(22.2 \%)\end{array}$ & $\begin{array}{l}135(74.2 \%) \\
123(77.8 \%)\end{array}$ & 0.430 \\
\hline Largest tumor location & $\begin{array}{l}\text { Ureter } \\
\text { Pelvis }\end{array}$ & $\begin{array}{l}132 \\
208\end{array}$ & $\begin{array}{l}48(36.4 \%) \\
34(16.3 \%)\end{array}$ & $\begin{array}{l}84(63.6 \%) \\
174(83.7 \%)\end{array}$ & $<0.001 *$ \\
\hline Pathological T stage & $\begin{array}{l}\text { Ta-TI } \\
\text { T2-T4 }\end{array}$ & $\begin{array}{l}124 \\
217\end{array}$ & $\begin{array}{l}19(15.3 \%) \\
63(29.0 \%)\end{array}$ & $\begin{array}{l}105(84.7 \%) \\
154(7 \mid \%)\end{array}$ & $0.004 *$ \\
\hline Tumor grade & $\begin{array}{l}\text { Low } \\
\text { High }\end{array}$ & $\begin{array}{l}93 \\
248\end{array}$ & $\begin{array}{l}8(8.6 \%) \\
74(29.8 \%)\end{array}$ & $\begin{array}{l}85(91.4 \%) \\
174(70.2 \%)\end{array}$ & $<0.001 *$ \\
\hline Lymph node status & $\begin{array}{l}\text { No or Nx } \\
\text { NI }\end{array}$ & $\begin{array}{l}314 \\
27\end{array}$ & $\begin{array}{l}74(23.6 \%) \\
8(29.6 \%)\end{array}$ & $\begin{array}{l}240(76.4 \%) \\
19(70.4 \%)\end{array}$ & 0.479 \\
\hline LVI & $\begin{array}{l}\text { No } \\
\text { Yes }\end{array}$ & $\begin{array}{l}307 \\
34\end{array}$ & $\begin{array}{l}76(24.8 \%) \\
6(17.6 \%)\end{array}$ & $\begin{array}{l}23 \mathrm{I}(75.2 \%) \\
28(82.4 \%)\end{array}$ & 0.357 \\
\hline Architecture & $\begin{array}{l}\text { Papillary } \\
\text { Sessile }\end{array}$ & $\begin{array}{l}279 \\
62\end{array}$ & $\begin{array}{l}55(19.7 \%) \\
27(43.5 \%)\end{array}$ & $\begin{array}{l}224(80.3 \%) \\
35(56.5 \%)\end{array}$ & $<0.001 *$ \\
\hline Squamous differentiation & $\begin{array}{l}\text { No } \\
\text { Yes }\end{array}$ & $\begin{array}{l}296 \\
45\end{array}$ & $\begin{array}{l}66(22.3 \%) \\
16(35.6 \%)\end{array}$ & $\begin{array}{l}230(77.7 \%) \\
29(64.4 \%)\end{array}$ & 0.053 \\
\hline Glandular differentiation & $\begin{array}{l}\text { No } \\
\text { Yes }\end{array}$ & $\begin{array}{l}323 \\
18\end{array}$ & $\begin{array}{l}74(22.9 \%) \\
8(44.4 \%)\end{array}$ & $\begin{array}{l}249(77.1 \%) \\
10(55.6 \%)\end{array}$ & $0.037^{*}$ \\
\hline Sarcomas differentiation & $\begin{array}{l}\text { No } \\
\text { Yes }\end{array}$ & $\begin{array}{l}319 \\
22\end{array}$ & $\begin{array}{l}7 \mathrm{I}(22.3 \%) \\
\mathrm{II}(50 \%)\end{array}$ & $\begin{array}{l}248(77.7 \%) \\
\text { I I(50\%) }\end{array}$ & $0.003 *$ \\
\hline PRF & $\begin{array}{l}\text { No CKD } \\
\text { Early CKD } \\
\text { End CKD }\end{array}$ & $\begin{array}{l}139 \\
147 \\
15\end{array}$ & $\begin{array}{l}29(20.9 \%) \\
39(26.5 \%) \\
4(26.7 \%)\end{array}$ & $\begin{array}{l}110(79.1 \%) \\
108(73.5 \%) \\
11(73.3 \%)\end{array}$ & 0.515 \\
\hline Multifocality & $\begin{array}{l}\text { No } \\
\text { Yes }\end{array}$ & $\begin{array}{l}286 \\
55\end{array}$ & $\begin{array}{l}70(24.5 \%) \\
12(2 \mid .8 \%)\end{array}$ & $\begin{array}{l}216(70 \%) \\
43(78.2 \%)\end{array}$ & 0.673 \\
\hline Largest tumor size & $\begin{array}{l}<4 \\
\geq 4\end{array}$ & $\begin{array}{l}118 \\
222\end{array}$ & $\begin{array}{l}3 I(26.3 \%) \\
50(22.5 \%)\end{array}$ & $\begin{array}{l}87(73.7 \%) \\
172(77.5 \%)\end{array}$ & 0.440 \\
\hline
\end{tabular}

Note: *Statistically significant.

Abbreviations: BMI, Body Mass Index; PRF, preoperative renal function; CKD, chronic kidney disease; LVI, lymphovescular invasion. 
the presence of glandular differentiation $(\mathrm{p}=0.037)$ or sarcoma differentiation $(\mathrm{p}=0.003)$.

\section{SOX2 Is An Independent Prognostic Factor Of Poor CSS And DFS}

During the follow-up period, 97 patients died due to UTUC-related causes, and intravesical and local recurrences occurred in $82(24.0 \%)$ and $13(3.8 \%)$ patients, respectively. Moreover, new contralateral UTUC tumors occurred in $8(2.35 \%)$ patients. Kaplan-Meier plots and log rank tests showed that SOX2 expression was positively associated with decreased CSS $(\mathrm{p}=0.032)$ and DFS $(p=0.018)$ (Figure $2 B$ and C). In a multivariable Cox model adjusted for sex, pathological tumor stage, tumor grade, lymph node status, LVI, architecture, glandular differentiation and sarcoma differentiation, SOX2 positivity represented an independent risk factor for poor CSS $(\mathrm{HR}=1.585 ; 95 \%$ CI 1.002-2.508; $\mathrm{p}=$ 0.049) (Table 2). Additionally, in a multivariable Cox model adjusted for sex, tumor grade, lymph node status and LVI, SOX2 expression represented an independent risk factor for poor DFS (HR $=1.442$; $95 \%$ CI $1.031-$ 2.017; $\mathrm{p}=0.032$ ) (Table 3$)$. In constructed nomograms, the c-index of the model with SOX2 was higher than the model without SOX2 both for CSS $(0.685$ vs 0.662 , $\mathrm{z}=5.090, \mathrm{p}<0.001)$ and DFS (0.616 vs $0.596, \mathrm{z}=5.739$, $\mathrm{p}<0.001)$ (Supplementary Figure S1).

\section{Specific shRNA Downregulated The Expression Of SOX2 In UTUC Cells}

UM-UC-14 and MC-SV-HUC T2 cells were cultured and transfected with a SOX2-specific shRNA or negative control shRNA. At $48 \mathrm{~h}$ after transfection, the relative expression level of SOX2 was analyzed by qRT-PCR and Western blotting. The results showed that the relative levels of SOX2 inthe UM-UC-14 (Figure 3A) and MC-SV-HUC T2 (Figure 3B) cells were significantly downregulated by the SOX2-specific shRNA.

\section{Knocking Down SOX2 Expression Inhibited Proliferationin UTUC Cells}

We further determined whether SOX2 promotes cell proliferation in UTUC. Cell proliferation changes in UTUC cells were determined using an EdU assay. Cell growth arrest was observed in UM-UC-14 (Figure $3 \mathrm{C}$ and $\mathrm{E}$ ) and MC-SV-HUC T2 (Figure 3D and F) cells. These results confirmed that SOX2 promotes cell proliferation in UTUC.

\section{Knocking Down SOX2 Expression May Inhibited The Stemness Of UTUC Cells}

We further determined whether SOX2 promotes cell stemness in UTUC. Cell stemness changes in UTUC cells were determined using a sphere-forming assay. Cell growth arrest was observed in UM-UC-14 (Figure 3G) and

Table 2 Univariable And Multivariable Analyses Of The Correlations Between SOX2 Expression And CSS In Patients With UTUC

\begin{tabular}{|c|c|c|c|c|}
\hline \multirow[t]{2}{*}{ Variables } & \multicolumn{2}{|c|}{ Univariable Analyses } & \multicolumn{2}{|c|}{ Multivariable Analyses } \\
\hline & HR (95\% Cl) & $\mathbf{p}$ & HR (95\% Cl) & $\mathbf{p}$ \\
\hline Age & $1.005(0.986-1.025)$ & 0.584 & & \\
\hline Gender (Male) & $1.981(1.321-2.969)$ & $0.001 *$ & 2.301 (1.497-3.537) & $<0.001 *$ \\
\hline BMI $(\geq 24.5)$ & $1.042(0.699-1.552)$ & 0.842 & & \\
\hline PRF $(e G F R<30)$ & $0.776(0.543-1.019)$ & 0.165 & & \\
\hline Largest tumor location (Pelvis) & $0.866(0.578-1.297)$ & 0.866 & & \\
\hline Multifocality & $0.832(0.503-1.445)$ & 0.552 & & \\
\hline Largest tumor size $(\geq 4)$ & $1.257(0.820-1.938)$ & 0.293 & & \\
\hline Pathological T stage ( $\geq 2$ ) & $1.829(1.160-2.884)$ & $0.009 *$ & $1.213(0.709-2.077)$ & $0.48 I$ \\
\hline Tumor grade (High) & $1.714(1.159-2.534)$ & $0.007^{*}$ & $1.075(0.592-1.952)$ & 0.813 \\
\hline Lymph node status & $3.779(2.262-6.314)$ & $<0.00 I^{*}$ & $3.013(1.654-5.488)$ & $<0.001^{*}$ \\
\hline LVI & $2.158(0.943-2.575)$ & $0.005^{*}$ & $2.143(1.20 I-3.825)$ & $0.010 *$ \\
\hline Architecture (Sessile) & $2.456(1.588-3.798)$ & $<0.00 I^{*}$ & $1.58 \mid(0.928-2.694)$ & 0.092 \\
\hline Squamous differentiation & $1.618(0.945-2.711)$ & 0.080 & & \\
\hline Glandular differentiation & $2.301(1.063-4.981)$ & $0.034 *$ & $1.289(0.569-2.918)$ & 0.970 \\
\hline Sarcomas differentiation & $2.255(1.202-4.225)$ & $0.011 *$ & $0.014(0.495-2.077)$ & 0.543 \\
\hline SOX2 positive & $1.589(1.036-2.436)$ & $0.034 *$ & $1.585(1.002-2.508)$ & $0.049 *$ \\
\hline
\end{tabular}

Note: *Statistically significant.

Abbreviations: BMI, body mass index; PRF, preoperative renal function; LVI, lymphovescular invasion. 
Table 3 Univariable And Multivariable Analyses Of The Correlations Between SOX2 Expression And DFS In Patients With UTUC

\begin{tabular}{|c|c|c|c|c|}
\hline \multirow[t]{2}{*}{ Variables } & \multicolumn{2}{|c|}{ Univariable Analyses } & \multicolumn{2}{|c|}{ Multivariable Analyses } \\
\hline & HR (95\% Cl) & $p$ & HR (95\% Cl) & p \\
\hline Age & $0.993(0.979-1.007)$ & 0.300 & & \\
\hline Gender (Male) & $1.539(1.140-2.078)$ & $0.005^{*}$ & $1.746(1.282-2.377)$ & $<0.001 *$ \\
\hline $\mathrm{BMI}(\geq 24.5)$ & I.I05 (0.8I7-I.494) & 0.516 & & \\
\hline PRF $(e G F R<30)$ & I.00I (0.77I-I.300) & 0.994 & & \\
\hline Largest tumor location (Pelvis) & $0.769(0.569-1.040)$ & 0.088 & & \\
\hline Multifocality & I.I $47(0.782-1.68 I)$ & 0.483 & & \\
\hline Largest tumor size $(\geq 4)$ & $1.063(0.776-1.457)$ & 0.702 & & \\
\hline Pathological T stage $(\geq 2)$ & $1.310(0.952-1.802)$ & 0.097 & & \\
\hline Tumor grade (High) & $1.722(1.178-2.519)$ & $0.005^{*}$ & $1.700(1.136-2.544)$ & $0.010^{*}$ \\
\hline Lymph node status & $1.882(1.166-3.029)$ & $0.010 *$ & $1.600(0.982-2.604)$ & 0.059 \\
\hline LVI & $1.730(1.105-2.708)$ & $0.016 *$ & $1.656(1.052-2.605)$ & $0.029 *$ \\
\hline Architecture (Sessile) & $1.389(0.970-1.990)$ & 0.073 & & \\
\hline Squamous differentiation & 1.021 (0.652-I.599) & 0.927 & & \\
\hline Glandular differentiation & $1.697(0.920-3.131)$ & 0.090 & & \\
\hline Sarcomas differentiation & $1.472(0.852-2.545)$ & 0.166 & & \\
\hline SOX2 positive & 1.477 (I.064-2.052) & $0.020 *$ & $1.442(1.031-2.017)$ & $0.032 *$ \\
\hline
\end{tabular}

Note: *Statistically significant.

Abbreviations: BMI, body mass index; PRF, preoperative renal function; LVI, lymphovescular invasion.

MC-SV-HUC T2 (Figure 3H) cells. These results confirmed that SOX2 may promotes cell stemness in UTUC.

\section{Knocking Down SOX2 Expression Inhibited Cell Migration And Invasion In UTUC Cells}

We further determined whether SOX2 regulates cell migration and invasion in UTUC cells. The migratory abilities of UTUC cells were evaluated using a wound healing assay. Inhibited cell migration was observed in UM-UC-14 and MC-SV-HUC T2 cells with silenced SOX2 (Figure 4A and B). The invasive abilities of UTUC cells were assessed using a transwell assay. Inhibited cell invasion was observed in UM-UC-14 and MC-SV-HUC T2 cells with silenced SOX2 (Figure 4C and D). The results indicated that SOX2 is essential for cell migration and invasion of UTUC.

\section{Knocking Down SOX2 Inhibited The Tumorigenicity Of UTUC Cells}

Finally, we determined whether SOX2 regulatesthetumorigenicity of UTUC cells by evaluating the generation of xenografts. We found that knocking down SOX2 expression inhibited the tumorigenicity of UTUC cells in vivo. Tumors collected from mice were examined and measured (Figure 5A). There was no significant difference in body weight between the shRNA-SOX2 group and the shRNA-NC group (Figure 5B). Tumor growth in the shRNA-NC group was faster than that in the shRNA1-SOX2 group (Figure 5C). Tumor weight in the $\mathrm{NC}$ treatment group was greater than that in the shSOX2 group (Figure 5D). We found that shRNA-SOX2 decreased SOX2 expression in UTUC cells in vivo (Figure 5E and F). These results demonstrated that SOX2 promotes the tumorigenicity of UTUC cells.

\section{Discussion}

Despite great improvements in the surgical and medical management of UTUC, disease etiology remains poorly understood. In the present study, we analyzed SOX2 expression in UTUC tissue samples as well as the prognostic relevance of SOX2 expression in patients with UTUC who had undergone RNU. Additionally, the roles of SOX2 in the proliferation, migration, invasion and tumorigenicity of cell lines was analyzed. We found that SOX2 expression was upregulated in UTUC tissue samples compared with paired-adjacent nontumorous tissue samples and correlated with advanced pathological features, indicating that SOX2 could be an independent predictive risk factor for oncological outcomes. Furthermore, inhibited malignant phenotypes were observed in SOX2-specific shRNA-transfected UTUC cells. These findings indicated that SOX2 may play key roles in the progression and development of UTUC. 

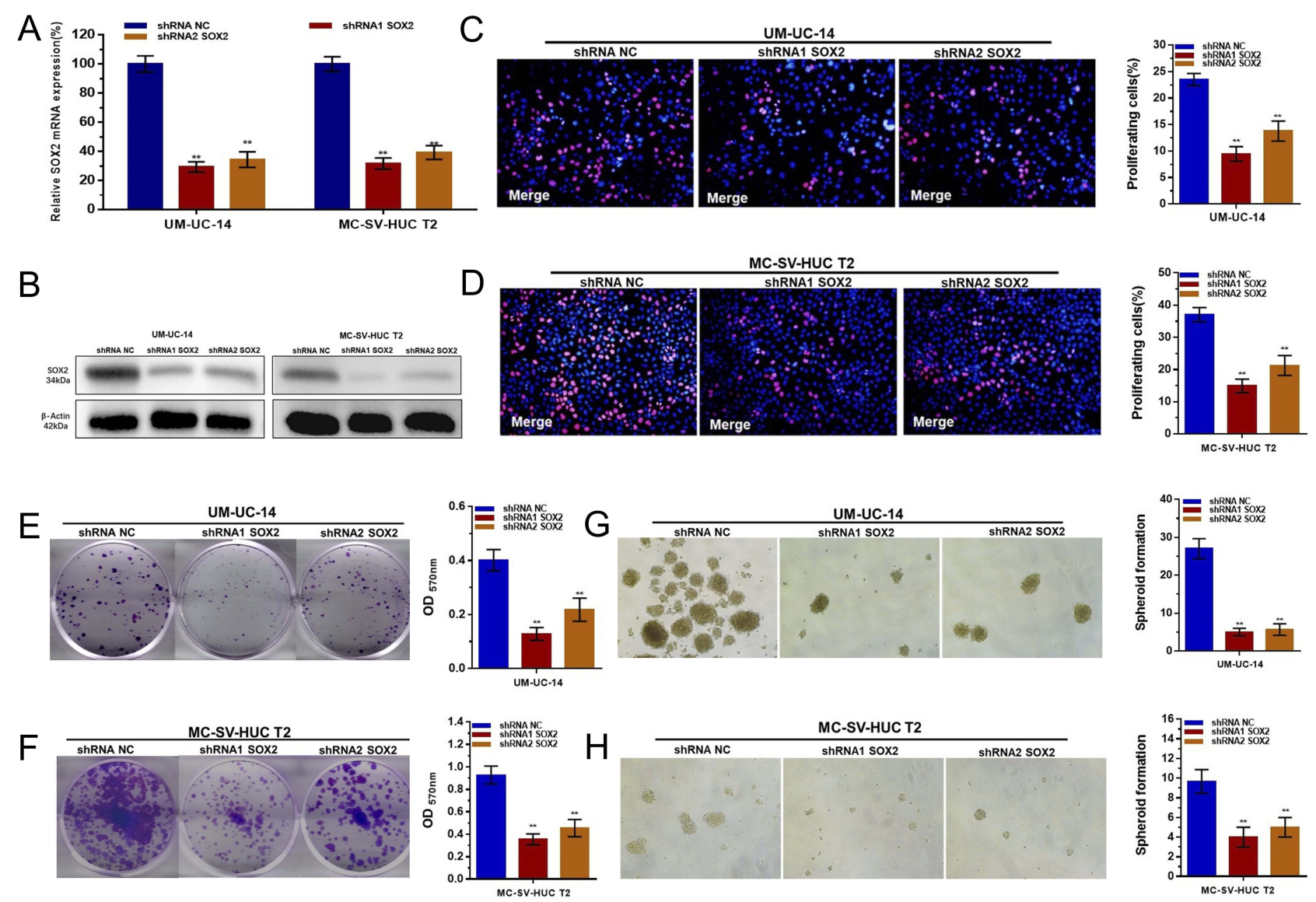

Figure 3 Effect of SOX2 on the proliferation and stemness of UTUC cells. (A and B): SOX2-specific shRNAs significantly decreased the expression level of SOX2 in UMUC-I4 and MC-SV-HUC T2 cells. (C and D): Cell proliferation changes in UTUC cells were determined using an EdU assay. (E and F): Cell proliferation changes in UTUC cells were determined using a colony-formation assay. (G and $\mathbf{H})$ : The cell stemness of UTUC cells was determined using a sphere-forming assay. Cell proliferation was inhibited by silencing SOX2 in UM-UC-14 and MC-SV-HUC T2 cells. Data are shown as the mean \pm SD. **p $<0.01$.

A

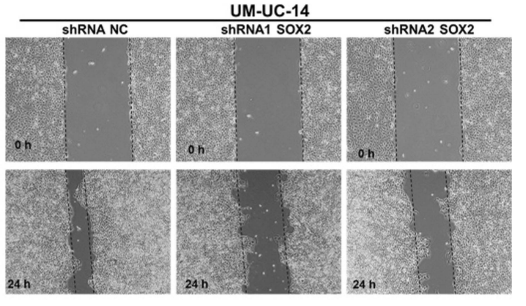

C

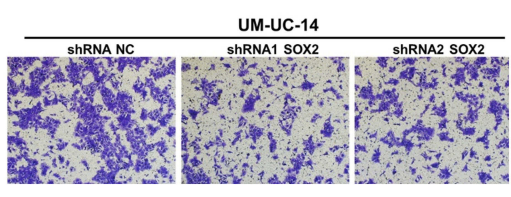

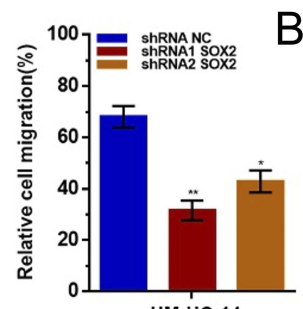

B
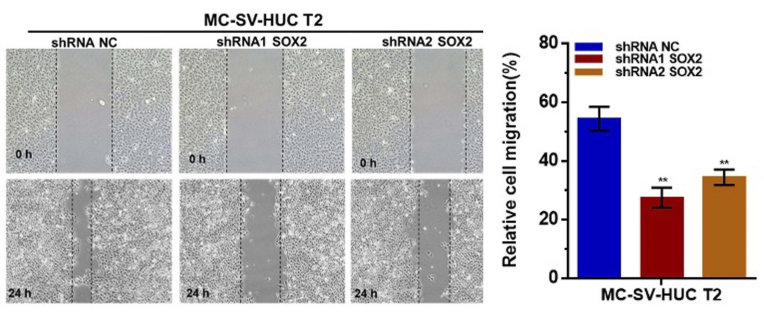

UM-UC-14

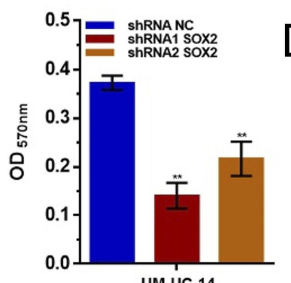

D
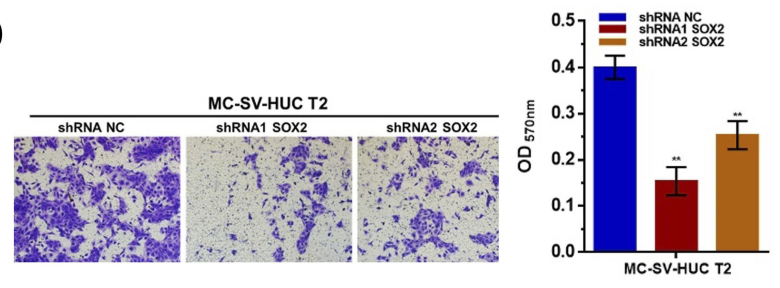

Figure 4 Effect of SOX2 on the migration and invasion of UTUC cells. (A and B): The migratory abilities of UTUC cells were determined using a wound healing assay. Cell migration was inhibited by silencing SOX2 in UM-UC-14 and MC-SV-HUC T2 cells. (C and D): The invasive abilities of UTUC cells were determined using a transwell assay. Cell invasion was inhibited by silencing SOX2 in UM-UC-I4 and MC-SV-HUC T2 cells. Data are shown as the mean \pm SD. ${ }^{*} P<0.05 ; * * p<0.01$.

Together with SOX1 and SOX3, SOX2, a transcription factor, belongs to the SOXB1 group in the SOX family. ${ }^{8}$
Compared to healthy tissue, tumor tissue has been reported to have an upregulation of SOX2 in various cancer 


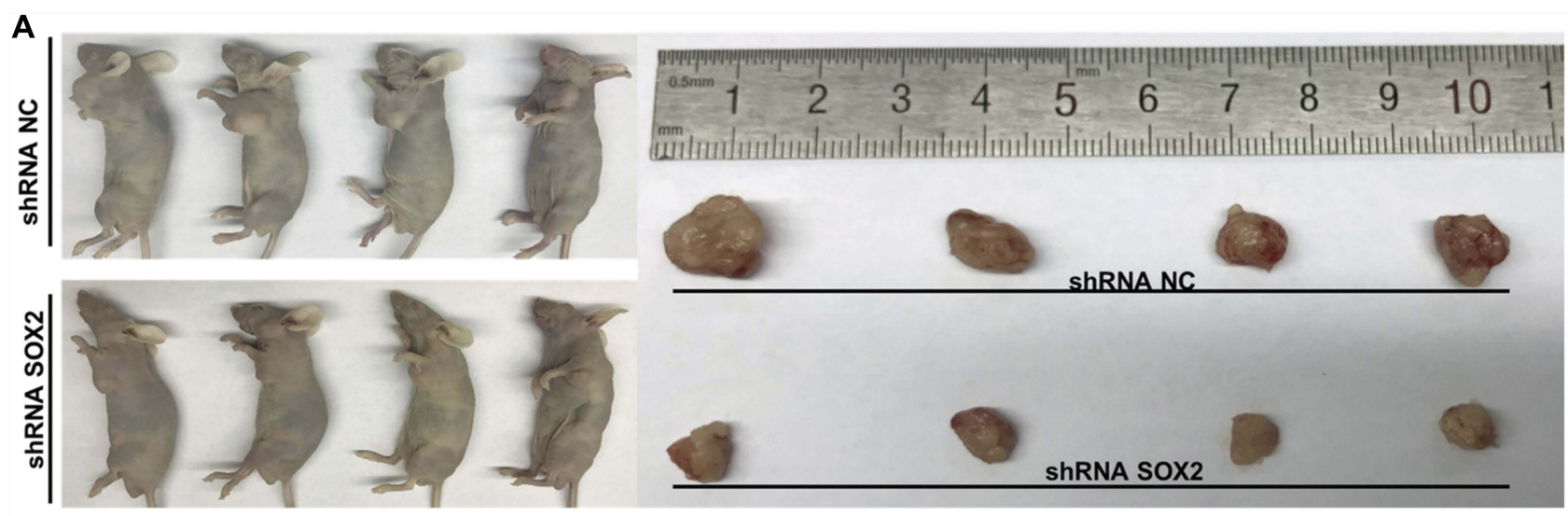

B
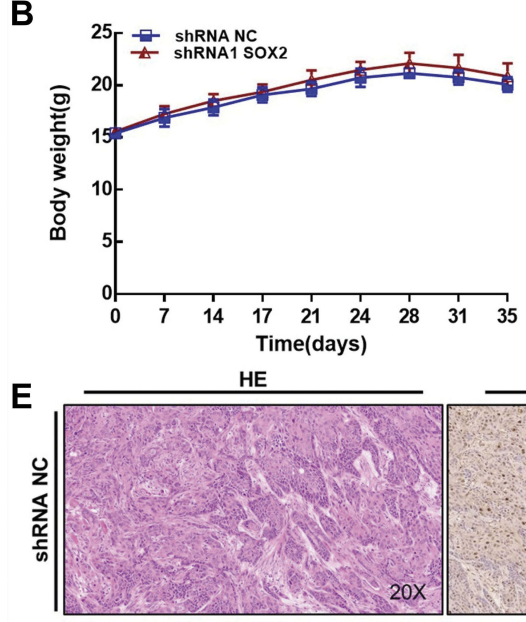

HE

C

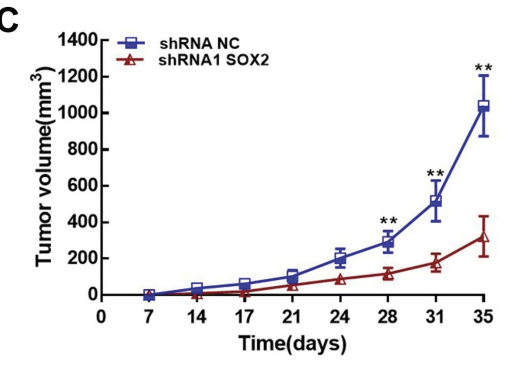

sox2

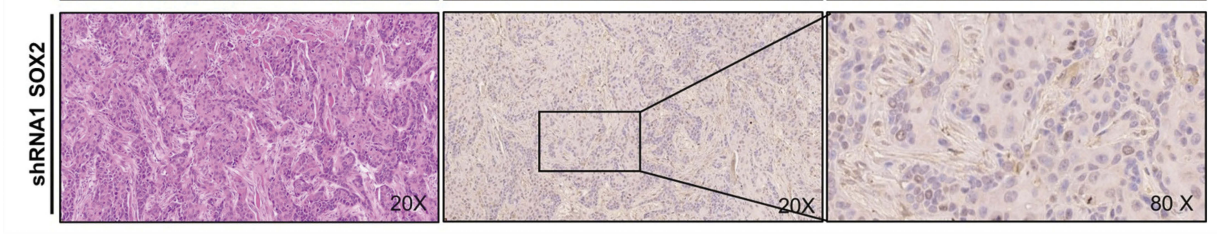

D

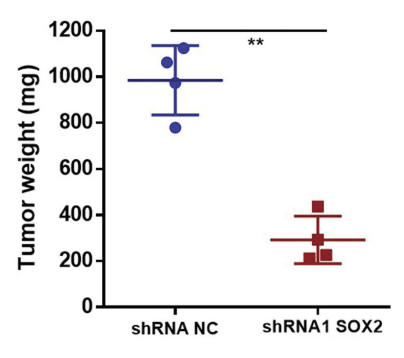

Figure 5 Effect of SOX2 on the tumorigenicity of UTUC cells. (A): Tumors collected from mice are shown. (B): The weights of nude mice in different groups were measured and analyzed. (C): Tumor volume curves of different groups were measured and analyzed. (D): Tumor weights in different groups were measured and analyzed. Knocking down SOX2 expression inhibited the tumorigenicity of UTUC cells in vivo. (E and F): shRNA-SOX2 decreased SOX2 expression in UTUC cells in vivo. Data are shown as the mean $\pm \mathrm{SD}$. $* * \mathrm{p}<0.01$.

entities. ${ }^{9,18}$ Similar results were obtained in our study. Nuclear expression of SOX2 was detected in the tumor cells of $82(24.0 \%)$ UTUC patients, which was higher than the rate of $19 \%(24 / 125)$ reported in a previous study. ${ }^{15}$ We also found that a high expression level of SOX2 was significantly associated with poor DFS and CSS, which validates the results in previous studies that showed that increased expression of SOX2 was associated with poor oncological outcomes. ${ }^{15,19-22}$ However, in gastric cancer and squamous cell lung cancer, SOX2 has been reported to be associated with improved outcomes. ${ }^{23,24}$ However, the increased expression of SOX2 in our study was correlated with advanced pathological features, such as high pathological T stage, high tumor grade, sessile architecture and the presence of poor differentiation, which was in line with the results of a previous IHC study of 125 UTUC patients. ${ }^{15}$ These results suggest that SOX2 may be a novel player in the state of UTUC.

To understand the biological functions of SOX2, we detected cell proliferation, migration, invasion and tumorigenicity in related UTUC cell lines. Our results indicated that knocking down SOX2 expression could inhibit malignant phenotypes, and these results were in line with those of previous studies. Gen et $\mathrm{al}^{9}$ observed that SOX2 expression is high in esophageal squamous cell carcinoma cell lines, which have amplification of the SOX2 gene, and that SOX2 
promotes cell proliferation. Similar results have been obtained in pancreatic cancer and lung cancer. ${ }^{25,26}$ EMT is a process in which epithelial cells obtain migratory and invasive properties. Sun et $\mathrm{al}^{10}$ demonstrated that SOX2 overexpression in hepatocellular carcinoma causes active EMT and increases invasion and sphere and colony formation capacities. In human teratocarcinoma, Drakulic et $\mathrm{al}^{27}$ demonstrated that the overexpression of SOX2 increases cell migration in vitro. In a different study of breast cancer, the authors found that knocking out the SOX2 gene impairs cell proliferation, migration and invasion. ${ }^{28}$ In lung cancer, SOX2-overexpressing LHK2 and A549 cell lines show higher tumorigenicity than control cell lines. These results confirm that SOX2 may play important regulatory roles in the progression and development of UTUC. However, the molecular mechanism underlying SOX2 upregulation in UTUC still needs to be studied in future works.

Cancer stem-like cells (CSCs), which have the principal properties of self-renewal, tumor initiation ability and long-term repopulation potential, have been found in a variety of human malignancies, including $\mathrm{UCB},{ }^{11,14,29}$ which is recognized as an uncommon type of UC that is potentially distinct from UTUC. ${ }^{30}$ CSCs contribute to tumor recurrence and metastasis and make complete tumor cell elimination challenging. Moreover, various studies have demonstrated important roles for SOX2 in maintaining CSCs, ${ }^{11,17,19,21,31-39}$ which highlights this transcription factor as an attractive target for cancer therapy. ${ }^{18}$

\section{Conclusion}

The expression level of SOX2 is increased in UTUC tissue samples compared with paired-adjacent nontumorous tissue samples. SOX2 expression is an independent predictive factor for poor DFS and CSS, which is likely due to the ability of SOX2 to induce cell growth and metastasis in UTUC cells. The molecular mechanism underlying SOX2 upregulation in UTUC still needs to be studied in future works.

Cumulatively, these findings indicate that SOX2 plays an oncogenic role in UTUC and that SOX2 may be used as a potential prognostic factor and therapeutic target in UTUC.

\section{Acknowledgments}

The authors are appreciative of the donors who participated in this program. The UM-UC-14 cell line (SigmaAldrich, St. Louis, MO, USA) was a generous gift from
Prof. Kitamura of Toyama University, MC-SV-HUC T2 cells were purchased from ATCC (CRL-9519), and SVHUC-1 cells were purchased from the Institute of Cell Research (Chinese Academy of Sciences, Shanghai, China). This study was funded by the Beijing Natural Science Foundation (L182004 and 7152146), the Clinical Features Research of Capital (No. Z151100004015173), the Capital Health Research and Development of Special (2016-1-4077), and the Peking University Medicine Fund of Fostering Young Scholars' Scientific \& Technological Innovation (Fundamental Research Funds for the Central Universities, BMU2017PY009). Structured data processing was partially accomplished using Medbanks' approach (Medbanks Network Technology Co., Ltd., Beijing, China).

\section{Disclosure}

The authors declare that they have no conflicts of interest regarding this study.

\section{References}

1. Rouprêt M, Babjuk M, Compérat E, et al. European association of urology guidelines on upper urinary tract urothelial carcinoma: 2017 update. Eur Urol. 2018;73(1):111-122. doi:10.1016/j.eururo.2017.07.036

2. Rebecca LS, Kimberly DM, Ahmedin JD. Cancer statistics, 2017. CA Cancer J Clin. 2017;67(1):7-30. doi:10.3322/caac.21387

3. Li -C-C, Chang T-H, Wua W-J, et al. significant predictive factors for prognosis of primary upper urinary tract cancer after radical nephroureterectomy in Taiwanese patients. Eur Urol. 2008;54 (5):1127-1134. doi:10.1016/j.eururo.2008.01.054

4. Holmäng $\mathrm{S}$, Johansson $\mathrm{S}$. Urothelial carcinoma of the upper urinary tract: comparison between the WHO/ISUP 1998 consensus classification and WHO 1999 classification system. Urology. 2005;66 (2):274-278. doi:10.1016/j.urology.2005.03.011

5. Lughezzani G, Cisbarn J. Temporal stage and grade migration in surgically treated patients with upper tract urothelial carcinoma. BJU Int. 2010;105 (6):799-804. doi:10.1111/j.1464-410X.2009.08818.x

6. Vitaly M, Shariat SF, Matin SF, et al. Outcomes of radical nephroureterectomy: a series from the Upper Tract Urothelial Carcinoma Collaboration. Cancer. 2010;115(6):1224-1233. doi:10.1002/cncr.24135

7. Favaretto RL, Shariat SF, Chade DC, et al. The effect of tumor location on prognosis in patients treated with radical nephroureterectomy at Memorial Sloan-Kettering Cancer Center. Eur Urol. 2010;58(4):574-580. doi:10.1016/j.eururo.2010.07.003

8. Collignon J, Sockanathan S, Hacker A, et al. A comparison of the properties of Sox-3 with sry and two related genes, Sox-1 and Sox-2. Development. 1996;122(2):509-520. PMID:8625802.

9. Ye X, Wu F, Wu C, et al. $\beta$-Catenin, a Sox 2 binding partner, regulates the DNA binding and transcriptional activity of Sox 2 in breast cancer cells. Cell Signal. 2014;26(3):492-501. doi:10.1016/j.cellsig.2013.11.023

10. Sun C, Sun L, Li Y, Kang X, Zhang S, Liu Y. Sox2 expression predicts poor survival of hepatocellular carcinoma patients and it promotes liver cancer cell invasion by activating slug. Med Oncol. 2013;30(2):503. doi:10.1007/s12032-013-0503-1

11. Zhu F, Qian W, Zhang H, et al. SOX2 is a marker for stem-like tumor cells in bladder cancer. Stem Cell Rep. 2017;9(2):429-437. doi:10.1016/j.stemcr.2017.07.004 
12. Beck B, Blanpain C. Unravelling cancer stem cell potential. Nat Rev Cancer. 2013;13(10):727-738. doi:10.1038/nrc3597

13. Boumahdi S, Driessens G, Lapouge G, et al. SOX2 controls tumour initiation and cancer stem-cell functions in squamous-cell carcinoma. Nature. 2014;511(7508):246-250. doi:10.1038/nature13305

14. Ho P, Kurtova A, Chan KS. Normal and neoplastic urothelial stem cells: getting to the root of the problem. Nat Rev Urol. 2012;9 (10):583-594. doi:10.1038/nrurol.2012.142

15. Kitamura H, Torigoe T, Hirohashi Y, et al. Prognostic impact of the expression of ALDH1 and SOX2 in urothelial cancer of the upper urinary tract. Mod Pathol. 2013;26(1):117-124. doi:10.1038/ modpathol.2012.139

16. Ma YC, Zuo L, Chen JH, et al. Modified glomerular filtration rate estimating equation for Chinese patients with chronic kidney disease. $J$ Am Soc Nephrol. 2006;17(10):2937-2944. doi:10.1681/ASN.2006040 368

17. Nakatsugawa M, Takahashi A, Hirohashi Y, et al. SOX2 is overexpressed in stem-like cells of human lung adenocarcinoma and augments the tumorigenicity. Lab Invest. 2011;91(12):1796-1804. doi:10.1038/labinvest.2011.140

18. Hüser L, Novak D, Umansky V, Altevogt P, Utikal J. Targeting SOX2 in anticancer therapy. Expert Opin Ther Targets. 2018;22(12):983991. doi:10.1080/14728222.2018.1538359

19. Takeda K, Mizushima T, Yokoyama Y, et al. Sox2 is associated with cancer stem-like properties in colorectal cancer. Sci Rep. 2018;8 (1):17639. doi:10.1038/s41598-018-36251-0

20. Lee GJ, Lee H, Woo IS, et al. High expression level of SOX2 is significantly associated with shorter survival in patients with thymic epithelial tumors. Lung Cancer. 2019;132(undefined):9-16. doi:10. 1016/j.lungcan.2019.03.016

21. Muraki Y, Hasegawa T, Takeda D, et al. Induced pluripotent stem cell-related genes correlate with poor prognoses of oral squamous cell carcinoma. Anticancer Res. 2019;39(3):1205-1216. doi:10.21 873/anticanres. 13231

22. Gu W, Wang B, Wan F, et al. SOX2 and SOX12 are predictive of prognosis in patients with clear cell renal cell carcinoma. Oncol Lett. 2018;15(4):4564-4570. doi:10.3892/ol.2018.7828

23. Zhang X, Yu H, Yang Y, et al. SOX2 in gastric carcinoma, but not Hath1, is related to patients' clinicopathological features and prognosis. J Gastrointest Surg. 2010;14(8):1220-1226. doi:10.1007/ s11605-010-1246-3

24. Wilbertz T, Wagner P, Petersen K, et al. SOX2 gene amplification and protein overexpression are associated with better outcome in squamous cell lung cancer. Mod Pathol. 2011;24(7):944-953. doi:10.10 38/modpathol.2011.49

25. Chou YT, Lee CC, Hsiao SH, et al. The emerging role of SOX2 in cell proliferation and survival and its crosstalk with oncogenic signaling in lung cancer. Stem Cells. 2013;31(12):2607-2619. doi:10. $1002 /$ stem. 1518

26. Herreros-Villanueva M, Zhang JS, Koenig A, et al. SOX2 promotes dedifferentiation and imparts stem cell-like features to pancreatic cancer cells. Oncogenesis. 2013;2(undefined):e61. doi:10.1038/ oncsis. 2013.23
27. Drakulic D, Vicentic JM, Schwirtlich M, et al. The overexpression of SOX2 affects the migration of human teratocarcinoma cell line NT2/ D1. An Acad Bras Cienc. 2015;87(1):389-404. doi:10.1590/00013765201520140352

28. Liu K, Xie F, Gao A, et al. SOX2 regulates multiple malignant processes of breast cancer development through the SOX2/miR181a-5p, miR-30e-5p/TUSC3 axis. Mol Cancer. 2017;16(1):62. doi:10.1186/s12943-017-0632-9

29. Garg M. Urothelial cancer stem cells and epithelial plasticity: current concepts and therapeutic implications in bladder cancer. Cancer Metastasis Rev. 2015;34(4):691-701. doi:10.1007/s10555015-9589-6

30. Patel N, Arya M, Muneer A, et al. Molecular aspects of upper tract urothelial carcinoma. Urol Oncol. 2014;32(1):28.e11-e20. doi:10. 1016/j.urolonc.2012.10.002

31. Garros-Regulez L, Aldaz P, Arrizabalaga O, et al. mTOR inhibition decreases SOX2-SOX9 mediated glioma stem cell activity and temozolomide resistance. Expert Opin Ther Targets. 2016;20(4):393-405. doi:10.1517/14728222.2016.1151002

32. Song WS, Yang YP, Huang CS, et al. Sox2, a stemness gene, regulates tumor-initiating and drug-resistant properties in CD133positive glioblastoma stem cells. J Chin Med Assoc. 2016;79 (10):538-545. doi:10.1016/j.jcma.2016.03.010

33. Lee $\mathrm{SH}$, Oh $\mathrm{SH}$, Do SI, et al. SOX2 regulates self-renewal and tumorigenicity of stem-like cells of head and neck squamous cell carcinoma. Br J Cancer. 2014;111(11):2122-2130. doi:10.1038/ bjc. 2014.528

34. Li Y, Chen K, Li L, Li R, Zhang J, Ren W. Overexpression of SOX2 is involved in paclitaxel resistance of ovarian cancer via the PI3K/ Akt pathway. Tumour Biol. 2015;36(12):9823-9828. doi:10.1007/ s13277-015-3561-5

35. Hütz K, Mejías-Luque R, Farsakova K, et al. The stem cell factor SOX2 regulates the tumorigenic potential in human gastric cancer cells. Carcinogenesis. 2014;35(4):942-950. doi:10.1093/car$\operatorname{cin} /$ bgt410

36. Pietrobono S, Morandi A, Gagliardi S, et al. Down-regulation of SOX2 underlies the inhibitory effects of the triphenylmethane gentian violet on melanoma cell self-renewal and survival. J Invest Dermatol. 2016;136(10):2059-2069. doi:10.1016/j.jid.2016.06.610

37. Xu Y, Dong X, Qi P, et al. Sox2 communicates with tregs through CCL1 to promote the stemness property of breast cancer cells. Stem Cells. 2017;35(12):2351-2365. doi:10.1002/stem.2720

38. Lundberg IV, Edin S, Eklöf V, Öberg A, Palmqvist R, Wikberg M. SOX2 expression is associated with a cancer stem cell state and down-regulation of $\mathrm{CDX} 2$ in colorectal cancer. BMC Cancer. 2016;16(undefined):471. doi:10.1186/s12885-016-2509-5

39. Bareiss PM, Paczulla A, Wang H, et al. SOX2 expression associates with stem cell state in human ovarian carcinoma. Cancer Res. 2013;73(17):5544-5555. doi:10.1158/0008-5472.CAN-12-4177

\section{Publish your work in this journal}

Cancer Management and Research is an international, peer-reviewed open access journal focusing on cancer research and the optimal use of preventative and integrated treatment interventions to achieve improved outcomes, enhanced survival and quality of life for the cancer patient.
The manuscript management system is completely online and includes a very quick and fair peer-review system, which is all easy to use. Visit http://www.dovepress.com/testimonials.php to read real quotes from published authors. 